\title{
Delayed linkage to HIV care among asylum seekers in Quebec, Canada
}

Nadine Kronfli ${ }^{1,2^{*}}$ (D), Blake Linthwaite ${ }^{2}$, Nancy Sheehan ${ }^{1,3}$, Joseph Cox ${ }^{1,2}$, Isabelle Hardy ${ }^{4}$, Bertrand Lebouché ${ }^{1,2,5}$, Alexandra de Pokomandy ${ }^{1,2,5}$, Charles Frenette ${ }^{1}$, Michel Roger ${ }^{4,6}$ and Marina B. Klein ${ }^{1,2,7}$

\begin{abstract}
Background: Migrants represent an increasing proportion of people living with HIV in many developed countries. We aimed to describe the HIV care cascade and baseline genotypic resistance for newly diagnosed asylum seekers referred to the McGill University Health Centre (MUHC) in Montreal, Quebec, Canada.

Methods: We conducted a retrospective cohort study of patients linked to the MUHC from June 1, 2017 to October 31, 2018. We calculated the median time (days; interquartile range (IQR)) from: 1) entry into Canada to immigration medical examination (IME) (i.e. HIV screening); 2) IME to patient notification of diagnosis; 3) notification to linkage to HIV care (defined as a CD4 or viral load (VL) measure); 4) linkage to HIV care to combination antiretroviral therapy (CART) prescription; and 5) CART prescription to viral suppression (defined as a VL $<20$ copies/ $\mathrm{mL}$ ). We reviewed baseline genotypes and interpreted mutations using the Stanford University HIV Drug Resistance Database. We calculated the proportion with full resistance to $\geq 1$ antiretroviral.

Results: Overall, 43\% (60/139) of asylum seekers were newly diagnosed in Canada. Among these, 62\% were late presenters (CD4 $<350$ cells/ $\mu \mathrm{l})$, 22\% presented with advanced HIV (CD4 $<200$ cells/ $\mu \mathrm{l}$ ), and 25\% with high-level viremia (VL > 100,000 copies/ml). Median time from entry to IME: 27 days [IQR:13;55]; IME to notification: 28 days [IQR:21;49]; notification to linkage: 6 days [IQR:2;19]; linkage to CART prescription: 11 days [IQR:6;17]; and cART to viral suppression: 42 days [IQR:31;88]; 45\% were linked to HIV care within 30 days. One-fifth (21\%) had baseline resistance to at least one antiretroviral agent; the K103 N/S mutation was the most common mutation.

Conclusions: While the majority of newly diagnosed asylum seekers were late presenters, only $45 \%$ were linked to care within 30 days. Once linked, care and viral suppression were rapid. Delays in screening and linkage to care present increased risk for onward transmission, and in the context of 21\% baseline resistance, consideration of point-of-care testing and immediate referral at IME screening should be made.
\end{abstract}

Keywords: HIV cascade of care, Asylum seekers, Screening, Linkage to care, Viral suppression, HIV resistance

\section{Background}

Many developed countries have observed recent shifts in their HIV epidemics, with a disproportionate number of new HIV diagnoses occurring among migrant populations $[1,2]$. Migrants are at increased risk of HIV acquisition for several reasons. While many migrants leave countries with generalized HIV epidemics, the risk

\footnotetext{
* Correspondence: nadine.kronfli@mcgill.ca

'Department of Medicine, Division of Infectious Diseases and Chronic Viral IIlness Service, Glen site, McGill University Health Centre, 1001 Decarie Boulevard D02.4110, Montreal, Quebec H4A 3J1, Canada

${ }^{2}$ Research Institute of the McGill University Health Centre, Montreal, Quebec, Canada

Full list of author information is available at the end of the article
}

remains high post-migration as they often remain sexually active within migrant communities, where the HIV prevalence is higher than that of the receiving country [3]. Furthermore, changes in sexual behaviours postmigration, in combination with HIV-related stigma and discrimination, and the social disparities that accompany migration, all contribute to a higher risk of HIV acquisition during migration [4-6]. As treatment as prevention efforts expand and local attempts to eliminate HIV intensify, migrant populations remain vulnerable as they are frequently mobile, uninsured or unengaged in HIV care, and seldom the target of local prevention and

(c) The Author(s). 2019 Open Access This article is distributed under the terms of the Creative Commons Attribution 4.0 International License (http://creativecommons.org/licenses/by/4.0/), which permits unrestricted use, distribution, and reproduction in any medium, provided you give appropriate credit to the original author(s) and the source, provide a link to the Creative Commons license, and indicate if changes were made. The Creative Commons Public Domain Dedication waiver (http://creativecommons.org/publicdomain/zero/1.0/) applies to the data made available in this article, unless otherwise stated. 
treatment efforts, thereby potentially becoming a main source of new HIV infections [6].

Asylum seekers, refugee claimants and refugees represent an increasing proportion of people living with HIV in Canada [7]. Since 2010, Canada has processed a growing number of asylum claims made by individuals from HIV-endemic countries; the number of claims doubled from 2016 with over 50,000 processed in 2017 and 2018 alone [8]. While the province of Ontario has been the preferential refuge for most asylum seekers, Quebec surpassed Ontario during the past two years having processed approximately 25,000 asylum claims per year [8]. This shift is likely due to the higher influx of Haitian and other French-speaking African asylum seekers from the United States, as well as a higher number of irregular or unauthorized ports of entry in Quebec, where the Safe Third Country Agreement between the United States and Canada does not apply [9]. Under this Agreement, requests for refugee protection are required to be made in the first country of arrival (either Canada or the United States) [9].

All asylum seekers and refugee claimants must undergo an immigration medical examination (IME) in either Canada or overseas, respectively, that is administered by Immigration, Refugees and Citizenship Canada (IRCC) [10]. The IME includes a mandatory HIV screening test for all individuals 15 years of age and older, as well as for those under the age of 15 with known risk factors [11]. Immigration medical doctors, who perform the IMEs, facilitate linkage to HIV care among those who test positive. HIV-related care is assumed by the Interim Federal Health Program (IFHP), which provides limited and temporary health care coverage for in- and out-patient hospital services, further laboratory and diagnostic testing, and the costs of provincially-approved medications including combination antiretroviral therapy (cART) for asylum seekers, refugee claimants and certain other groups [12]. Asylum seekers, refugee claimants and refugees are not denied entry or residency in Canada based on a positive HIV diagnosis.

Data from IRCC indicate that while the proportion of HIV-positive diagnoses among all IME applicants has been stable in recent years, the overall number of people migrating to Canada has increased and, thus, the number of HIV-positive migrants to Canada has also increased [13]. This suggests that there should be heightened efforts to increase timely access to HIV services among migrant groups. A similar trend has been seen in Montreal, Quebec in the last three years. In 2015-2016, people from HIV-endemic countries represented only $15-20 \%$ of all new HIV diagnoses, whereas in 2017, represented 51\% (Personal communications with Dr. Sarah-Amélie Mercure, 2019 Jan 10). Conversely, the proportion of new HIV diagnoses among men who have sex with men decreased from over 60\% in 2015-2016 to 42\% in 2017 in Montreal.

The HIV care cascade describes successive health care steps specific to HIV infection, from diagnosis to linkage to care, to treatment uptake and viral suppression, that result in optimal health outcomes. Timely engagement in HIV care has important individual-level health benefits, results in decreased forward transmission, and is essential to meeting the UNAIDS 90-90-90 objectives [14]. While linkage to care has been previously defined as accessing HIV care within 90 days of diagnosis, the current goal as per the Centre for Disease Control and Prevention (CDC) is 30 days [15]. The HIV care cascade has rarely been studied among migrant populations and never among Canadian asylum seekers [16]. Our primary aim was to quantify time to each step in the HIV care cascade among asylum seekers referred for care in order to inform future targeted health promotion and intervention development. Our secondary aim was to determine baseline genotypic resistance among all referred patients.

\section{Methods}

\section{Study population and data collection}

The Chronic Viral Illness Service (CVIS) is a multidisciplinary clinic focused on the care of individuals with chronic viral infections, and is located at the McGill University Health Centre (MUHC) in Montreal, Quebec, Canada. In 2018, there were 1849 patients who were in active care at the CVIS for either HIV infection alone or concomitant with another viral infection such as hepatitis B or C. The MUHC is the primary HIV referral centre for $>75 \%$ of asylum seekers in Montreal.

All adult (18 years of age or older) patients living with HIV (with or without another viral co-infection) who were linked to HIV care at the CVIS between June 1, 2017 and October 31, 2018, and whose care was covered by the IFHP (i.e. asylum seekers), were included in this retrospective cohort study. Patients meeting the inclusion criteria were identified retrospectively by either: (1) direct written or verbal notification of patients to the principal investigator by other CVIS physicians; or (2) letters written by CVIS physicians to patients' designated immigration doctors; or (3) review of the CVIS social workers' lists of patients with IHFP coverage. Patients were censored on the date of transfer to another clinic or at their last clinic visit prior to November 2018. Patients were excluded if they were referred to the CVIS during the study period without the appropriate transfer of documents necessary to determine the primary HIV care cascade outcome measures $(n=5)$. This study was approved by the Research Institute of the McGill University Health Centre Research Ethics Board (MUHC 2019-5037). 
The CVIS maintains a clinical database and electronic medical records, both of which were the sources of information for all variables of interest. Retrospective reviews of patients' data were performed to collect baseline sociodemographic (age, sex, sexual orientation) and psychosocial (substance use including alcohol, comorbidities such as mental health conditions) information, patient migration trajectories (including entry date in Canada), HIV laboratory parameters including CD4 count and viral load (VL) at presentation, and baseline genotype testing (if $\mathrm{VL}>400$ copies $/ \mathrm{mL}$ ). The dates of IME screening and diagnosis notifications were obtained from documents from outside laboratories and designated immigration doctors, respectively. Given the retrospective nature of the study, patient consent was not obtained. Instead, authorization to access patient charts was obtained from the Director of Professional Services of the MUHC - Adult Sector.

\section{Outcome variables}

Among newly diagnosed asylum seekers, the primary outcome measures were median time in days from: (1) entry into Canada to IME screening; (2) IME screening to patient notification of diagnosis; (3) patient notification to linkage to HIV care (defined as either a CD4 cell count or VL measure); (4) linkage to initiation of cART (defined as the date a prescription was made for cART); and (5) initiation of cART to viral suppression (defined as a $\mathrm{VL}<20$ copies $/ \mathrm{mL}$ ). The proportion of late presenters $(\mathrm{CD} 4$ count $<350$ cells $/ \mu \mathrm{L})$, those with advanced HIV infection (CD4 count $<200$ cells $/ \mu \mathrm{L}$ ), and high-level viremia (VL $>100,000$ copies $/ \mathrm{mL}$ ) was calculated. Among asylum seekers who were previously diagnosed with HIV infection outside Canada, a similar cascade of care was determined; however, median time from entry into Canada to linkage to HIV care was the first calculated time interval. Asylum seekers with known HIV infection were referred directly to the MUHC through the Programme Régional d'Accueil et d'Intégration des Demandeurs d'Asile (PRAIDA), which has a mandate from the Ministère de la Santé et des Services Sociaux to meet the needs of asylum seekers throughout Quebec. The proportion of patients who were linked within 30, 60 and 90 days from IME screening (among newly diagnosed asylum seekers) and from arrival in Canada (among previously diagnosed asylum seekers) was determined. Retention in care at six months and one year was calculated as the proportion of patients who attended a clinic visit at least six and 12 months after entering care, respectively.

Baseline genotypes were reviewed and mutations were interpreted using the Stanford University HIV Drug Resistance Database (Stanford HIVdb) [17]. Secondary outcome measures included the proportion of patients with full resistance to at least one antiretroviral (reported per class: nucleoside reverse transcriptase inhibitors (NRTI), non-nucleoside reverse transcriptase inhibitors (NNRTI), protease inhibitors (PI) and integrase inhibitor (II)), and multidrug resistance (resistance to two or more drugs from different antiretroviral classes). Genotypic susceptibility scores (GSS) were calculated as the sum of the individual GSS for each antiretroviral agent in a patient's prescribed cART regimen following linkage to HIV care [18]. Based on GSS calculations by Frentz et al., each agent was given a score based on the level of resistance assigned by the Stanford HIVdb: $0,0.25,0.50,0.75$, or 1 for highlevel, intermediate, low-level, potential low-level, and susceptible, respectively [18]. A score of 3 or higher indicates a fully susceptible cART regimen. Only genotypes taken prior to or up to eight days after the start of a given cART regimen were considered when calculating GSS [18]. The proportion of patients with M184 V/I, K103 N/S, and K65R mutations, as well as the presence of thymidine analogue mutations (TAMs) were also reported. The proportion of patients with virologic failure (defined as the inability to achieve and maintain a $\mathrm{VL}<200$ copies/mL after 6 months of antiretroviral therapy) and the development of new resistance mutations were evaluated [19].

\section{Statistical analysis}

Summary statistics, medians and interquartile ranges (IQR) or counts and proportions, were calculated to describe the sample. All analyses were performed in R-3.5.1.

\section{Results}

\section{Patient characteristics}

A total of 139 asylum seekers were included with a median follow-up time of 9.7 [5.1, 12.2] months. Patient sociodemographic and clinical characteristics at initial visit are presented in Table 1 . Median age was 38 years, $63 \%$ were female, and $86 \%$ self-identified as heterosexual. A minority were co-infected with either hepatitis B or C while onethird had positive tuberculin skin tests. Over one-third of patients were of Haitian ethnicity and approximately onequarter were Nigerian; 84\% of all asylum seekers transited through the United States before entering Canada.

Overall, $43 \%$ of asylum seekers were newly diagnosed in Canada with a median CD4 count of 307 cells/ $\mu$ l and VL of 32,349 copies $/ \mathrm{mL}$ at presentation. Among these, $62 \%$ were late presenters $(\mathrm{CD} 4<350$ cells $/ \mu \mathrm{l}), 22 \%$ presented with advanced HIV $(\mathrm{CD} 4<200$ cells $/ \mu \mathrm{l})$, and $25 \%$ presented with high-level viremia $(\mathrm{VL}>100,000$ copies/ml); one patient was an elite controller. Primary prophylaxis for HIV-associated opportunistic infections (OI) was prescribed for $20 \%$ of newly diagnosed asylum seekers. Among those previously diagnosed outside Canada, 77\% were on CART at initial presentation; median CD4 count and VL were 621 cells $/ \mu \mathrm{l}$ and $<20$ copies $/ \mathrm{mL}$, respectively 
Table 1 Baseline characteristics of the study sample

\begin{tabular}{|c|c|c|c|}
\hline & Overall $(n=139)$ & $\begin{array}{l}\text { First diagnosed in } \\
\text { Canada }(n=60)\end{array}$ & $\begin{array}{l}\text { First diagnosed before } \\
\text { arrival to Canada }(n=79)\end{array}$ \\
\hline Age (median [IQR]) & $38[33 ; 45]$ & $37[33 ; 44]$ & $39[33 ; 47]$ \\
\hline \multicolumn{4}{|l|}{ Sex } \\
\hline Female & $88(63 \%)$ & $31(52 \%)$ & $57(72 \%)$ \\
\hline Male & $51(37 \%)$ & $29(48 \%)$ & $22(28 \%)$ \\
\hline \multicolumn{4}{|l|}{ Sexual orientation } \\
\hline Heterosexual & $120(86 \%)$ & $51(85 \%)$ & $69(87 \%)$ \\
\hline LGBTQ & $19(14 \%)$ & $9(15 \%)$ & $10(13 \%)$ \\
\hline \multicolumn{4}{|l|}{ Country of origin } \\
\hline \multicolumn{4}{|l|}{ Africa } \\
\hline Nigeria & $33(24 \%)$ & $12(20 \%)$ & $21(27 \%)$ \\
\hline Other & $54(39 \%)$ & $19(31 \%)$ & $36(46 \%)$ \\
\hline \multicolumn{4}{|l|}{ Latin America } \\
\hline Haiti & $48(34 \%)$ & $29(48 \%)$ & 19 (24\%) \\
\hline Other & $4(3 \%)$ & $0(0 \%)$ & $3(4 \%)$ \\
\hline History of sexual- or gender-based violence & $57(41 \%)$ & $25(42 \%)$ & $32(41 \%)$ \\
\hline Rape & $35(25 \%)$ & $16(26 \%)$ & $19(24 \%)$ \\
\hline 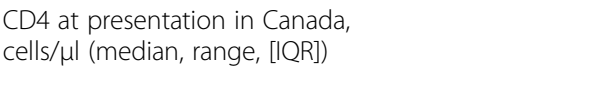 & $\begin{array}{l}415 \\
7-1221 \\
{[275 ; 656.5]}\end{array}$ & $\begin{array}{l}307 \\
11-811 \\
{[221 ; 401]}\end{array}$ & $\begin{array}{l}574 \\
7-1221 \\
{[382 ; 756]}\end{array}$ \\
\hline CD4 $<200$ & $22(16 \%)$ & $13(22 \%)$ & $9(11 \%)$ \\
\hline CD4 $<350$ & $52(37 \%)$ & $37(62 \%)$ & $15(19 \%)$ \\
\hline Baseline viral load, copies/ml (median, range, [IQR]) & $\begin{array}{l}1970, \\
<20->1 \text { million, }[<20 ; 41,313]\end{array}$ & $\begin{array}{l}\text { 32,349, } \\
<20->1 \text { million, } \\
{[7890 ; 100,594]}\end{array}$ & $\begin{array}{l}<20 \\
<20->1 \text { million, } \\
{[<20 ; 181]}\end{array}$ \\
\hline Ol at presentation & $1(1 \%)$ & $1(2 \%)$ & $0(0 \%)$ \\
\hline Requiring primary prophylaxis for OI & $23(16 \%)$ & $12(20 \%)$ & $10(13 \%)$ \\
\hline \multicolumn{4}{|l|}{ CART regimens, baseline } \\
\hline On CART & $61(44 \%)$ & $0(0 \%)$ & $61(77 \%)$ \\
\hline \multicolumn{4}{|l|}{ 3rd agent } \\
\hline NNRTI & $35(57 \%)$ & $0(0 \%)$ & $35(57 \%)$ \\
\hline $\mathrm{PI}$ & $5(8 \%)$ & $0(0 \%)$ & $5(8 \%)$ \\
\hline$\|$ & $16(26 \%)$ & $0(0 \%)$ & $16(26 \%)$ \\
\hline Unknown & $4(7 \%)$ & $0(0 \%)$ & $4(7 \%)$ \\
\hline Single tablet regimens & $41(67 \%)$ & $0(0 \%)$ & $41(67 \%)$ \\
\hline \multicolumn{4}{|l|}{ cART regimens, end of study period } \\
\hline On cART & $133(96 \%)$ & $58(97 \%)$ & $75(95 \%)$ \\
\hline \multicolumn{4}{|l|}{ 3rd agent } \\
\hline NNRTI & $8(6 \%)$ & $1(2 \%)$ & $7(9 \%)$ \\
\hline PI & $2(2 \%)$ & $0(0 \%)$ & $2(3 \%)$ \\
\hline$\|$ & $123(92 \%)$ & 57 (98\%) & $66(88 \%)$ \\
\hline Single tablet regimens & $103(77 \%)$ & $42(72 \%)$ & $61(81 \%)$ \\
\hline \multicolumn{4}{|l|}{ TST } \\
\hline Positive & 47 (34\%) & $16(27 \%)$ & $31(39 \%)$ \\
\hline Negative & $84(60 \%)$ & $41(68 \%)$ & $43(54 \%)$ \\
\hline Not done/missing & $8(6 \%)$ & $3(5 \%)$ & $5(6 \%)$ \\
\hline
\end{tabular}


Table 1 Baseline characteristics of the study sample (Continued)

\begin{tabular}{llll}
\hline & Overall $(n=139)$ & $\begin{array}{l}\text { First diagnosed in } \\
\text { Canada }(n=60)\end{array}$ & $\begin{array}{l}\text { First diagnosed before } \\
\text { arrival to Canada }(n=79)\end{array}$ \\
\hline Co-infection with HBV & $8(6 \%)$ & $4(7 \%)$ & $4(5 \%)$ \\
Co-infection with HCV & $1(0.7 \%)$ & $0(0 \%)$ & $1(1 \%)$ \\
\hline
\end{tabular}

$A R V$ antiretroviral, $C A R T$ combination antiretroviral therapy, HBV hepatitis B virus, $H C V$ hepatitis $C$ virus, I/ integrase inhibitor, IQR interquartile range, LGBTQ lesbian, gay, bisexual, transgender, and/or queer, NNRTI non-nucleoside reverse transcriptase inhibitor, Ol opportunistic infection, PI protease inhibitor, TST tuberculin skin test

among those on cART, and 242 cells/ $\mu$ and 41,190 copies/mL, respectively among those not on cART. However, $29 \%$ had detectable VLs at presentation (including six of the 61 persons taking cART) and 13\% required primary prophylaxis. Opportunistic infections were rare in both groups; one newly diagnosed asylum seeker was hospitalized for 11 days for cerebral toxoplasmosis.

\section{HIV cascade of care}

Among the 139 patients who were linked to care, 96\% were prescribed CART; five had not yet seen a physician by the end of the study period and one was an elite controller. The majority of patients $(77 \%)$ were prescribed a single-tablet regimen and an integrase inhibitor was the most commonly (92\%) prescribed third agent. Among those on cART and in care, $87 \%(87 / 100)$ were virallysuppressed at six months and 97\% (36/37) at one year after linkage, respectively; the proportion with virologic failure was $4 \%(4 / 100)$ at 6 months. All patients were retained in care at six months and one year.

Among newly diagnosed asylum seekers $(n=60)$, median time from entry into Canada to IME screening: 27 days [IQR: 13; 55]; IME screening to notification of diagnosis: 28 days [IQR: 21 ; 49]; notification to linkage: 6 days [IQR: 2; 9]; linkage to cART prescription: 11 days [IQR: 6; 17]; and cART prescription to viral suppression: 42 days [IQR: 31; 88] (Fig. 1a). Median time from entry to linkage to care was 80 days [IQR: 57; 102]. Overall,

\section{1a: Newly diagnosed asylum seekers}

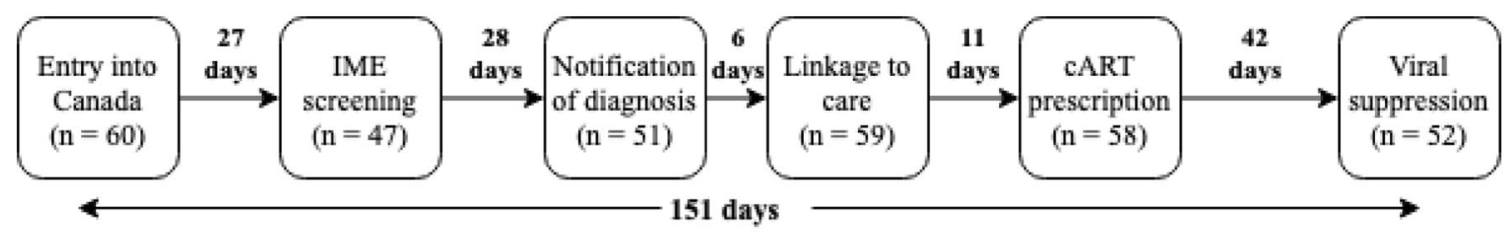

1b: Previously diagnosed asylum seekers on antiretroviral therapy

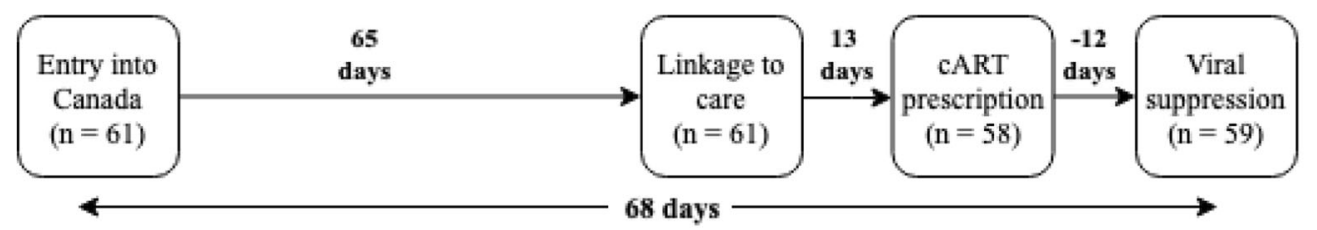

1c: Previously diagnosed asylum seekers not on antiretroviral therapy

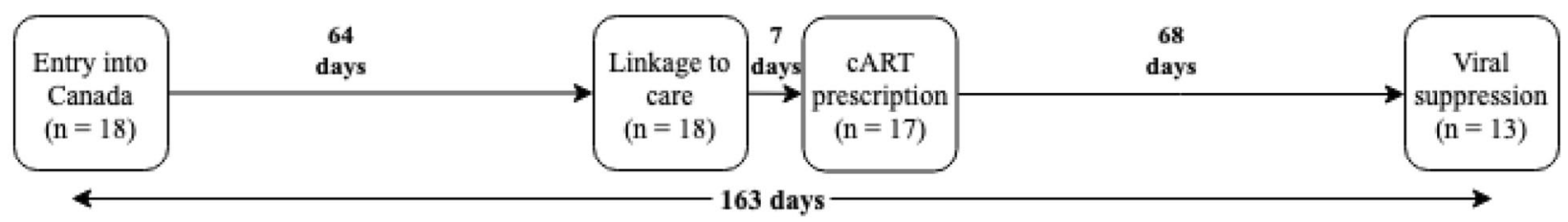

Fig. $\mathbf{1}$ HIV cascades of care among newly diagnosed asylum seekers $\mathbf{1 a}$, previously diagnosed asylum seekers on antiretroviral therapy $\mathbf{1} \mathbf{b}$, and previously diagnosed asylum seekers not on antiretroviral therapy 1c 
$45 \%$ of new diagnoses were linked within 30 days, $80 \%$ within 60 days and $90 \%$ within 90 days from HIV screening. Median time from entry into Canada to viral suppression was 151 days [IQR: 121; 216]. We did not have data regarding IME screening or notification of diagnosis among $22 \%(13 / 60)$ and $15 \%(9 / 60)$ of newly diagnosed asylum seekers, respectively.

Among previously diagnosed asylum seekers who were on cART at presentation $(n=61)$, time from entry to linkage: 65 days [IQR: 45; 86]; linkage to cART prescription: 13 days [IQR: 5; 24], and cART prescription to viral suppression: -12 days [IQR: -21 ; -4$]$ (Fig. 1b). Among these, $90 \%$ were virally suppressed at presentation. Overall, $20 \%$ of previous diagnoses on CART at presentation were linked within 30 days, $48 \%$ within 60 days and $79 \%$ within 90 days from entry into Canada. Median time from entry into Canada to viral suppression was 68 days [IQR: 48; 91].

Among previously diagnosed asylum seekers who were not on cART at presentation $(n=18)$, time from entry to linkage: 64 days [IQR: 22; 102]; linkage to cART prescription: 7 days [IQR: 4; 10], and cART prescription to viral suppression: 68 days [IQR: 28; 89] (Fig. 1c). Overall, $28 \%$ of previous diagnoses not on cART at presentation were linked within 30 days, $44 \%$ within 60 days and $67 \%$ within 90 days from entry into Canada. Median time from entry into Canada to viral suppression was 163 days [IQR: $141 ; 185]$.

\section{Antiretroviral resistance}

Baseline genotypes were available for 95\% (57/60) of newly diagnosed asylum seekers and 29\% (23/79) of previously diagnosed asylum seekers (i.e. all individuals who were viremic at presentation) (Table 2). Among newly diagnosed asylum seekers, $21 \%$ had baseline resistance to at least one antiretroviral agent while $35 \%$ of previously diagnosed asylum seekers had baseline ARV resistance. Baseline resistance to at least one NNRTI was the most commonly observed resistance (with $12 \%$ of newly diagnosed asylum seekers exhibiting K103 N/S mutations; of these, 5/7 were from Latin America and 2/ 7 were from Africa), followed by NRTI resistance. M184 V/I, K65R and TAMs were uncommon, as was multidrug resistance. One newly diagnosed patient, who was unknowingly prescribed functional monotherapy, developed full integrase inhibitor resistance (N155H, Q148R, S147G, E138K, and E92Q mutations). The median GSS was 3 [IQR 3; 3] for the entire study population. Among the four patients with virologic failure, one developed two new resistance mutations (M184 V and N155H).

\section{Discussion}

Our study retrospectively identified that the major bottleneck along the HIV cascade of care for Canadian asylum seekers was linkage to care. We observed that even in a system with a clear care pathway, a minority (45\%) of newly diagnosed asylum seekers were linked to care within 30 days - the current CDC standard [15]. The majority $(62 \%)$ of newly diagnosed asylum seekers presented with a CD4 count of $<350$ cells/ $\mu \mathrm{l}$, and an important minority (22\%) with advanced HIV infection (CD4 count $<200$ cells/ $\mu$ l) necessitating primary OI prophylaxis, which not only reflects findings from other

Table 2 Baseline antiretroviral resistance

\begin{tabular}{llll}
\hline & Overall $(n=139)$ & $\begin{array}{l}\text { First diagnosed in } \\
\text { Canada }(n=60)\end{array}$ & $\begin{array}{l}\text { First diagnosed before } \\
\text { arrival to Canada }(n=79)\end{array}$ \\
\hline HIV Genotype available & $80(58 \%)$ & $57(95 \%)$ & $23(29 \%)$ \\
& & Baseline antiretroviral resistance & $15(65 \%)$ \\
No & $60(75 \%)$ & $45(79 \%)$ & $8(35 \%)$ \\
Yes & $20(25 \%)$ & $12(21 \%)$ & $4(17 \%)$ \\
NRTI resistance & $6(8 \%)$ & $2(4 \%)$ & $5(22 \%)$ \\
NNRTI resistance & $17(21 \%)$ & $12(21 \%)$ & $0(0 \%)$ \\
PI resistance & $0(0 \%)$ & $0(0 \%)$ & $0(0 \%)$ \\
II resistance & $1(1 \%)$ & $1(2 \%)$ & $1(4 \%)$ \\
Multidrug resistance & $3(4 \%)$ & $2(4 \%)$ & $1(4 \%)$ \\
M184 V/I mutation & $3(4 \%)$ & $2(4 \%)$ & $4(17 \%)$ \\
K103 N/S mutation & $11(14 \%)$ & $7(12 \%)$ & $0(0 \%)$ \\
K65R mutation & $0(0 \%)$ & $0(0 \%)$ & $0(0 \%)$ \\
TAMs & $1(1 \%)$ & $1(2 \%)$ & \\
\hline
\end{tabular}

${ }^{a}$ The denominator for these proportions is the number of patients with available genotypic data (i.e. 80 for overall, 57 for first diagnosed in Canada, and 23 for first diagnosed before arrival to Canada)

II integrase inhibitor, NRTI nucleoside reverse transcriptase inhibitor, NNRTI non-nucleoside reverse transcriptase inhibitor, PI protease inhibitor, TAMs Thymidine analogue mutations 
European studies, but underscores the importance of timely linkage for individual health benefits [20-22]. That said, we found that rapid cART initiation once linked was possible, that retention was $100 \%$ at six and 12 months, and that viral suppression was achieved for almost all. We also observed that while the majority (77\%) of asylum seekers with known HIV infection arrived with a supply of cART, nearly one-third had a detectable HIV RNA at presentation, including $10 \%$ of those on cART. Even longer delays to linkage to care were observed among those with a prior HIV diagnosis. Delays in screening and care can increase the likelihood of onward transmission, and in the context of non-trivial baseline resistance ( $25 \%$ of the overall population), expediting screening and linkage to care to prevent transmission of resistant viruses becomes even more important.

Accelerating linkage to HIV care for newly diagnosed asylum seekers should be considered a priority going forward. The current system in Canada requires that all asylum seekers entering the country schedule an IME within 30 days of arrival [23]. In fact, we observed that the median time to the IME following arrival in Canada among newly diagnosed asylum seekers was 27 days, meaning that approximately 50\% received their IMEs after the IRCC cut-off. The reasons for this delay are unknown, but as asylum seekers are exempt from IME fees, this may be related to a lack of knowledge, a low perception of risk, competing priorities such as housing, or a shortage of immigration medical doctors [23, 24]. Currently, HIV testing required as part of the IME is not a point-of-care service; rather, all bloodwork is routinely done through community-based laboratories. Consequently, we observed an additional 28-day delay from the IME to a patient's notification of his/her new HIV diagnosis. Thereafter, the median time to initiation of cART following notification was only 17 days. These findings underscore that the major bottleneck along the HIV care cascade were proximal to disease notification, and while rapid cART initiation was possible, suggest that newly diagnosed asylum seekers were at risk of contributing to forward HIV transmission for a median of 72 days prior to the initiation of antiretrovirals. Knowing that migration itself can enhance sexual behaviours, particularly among men who have sex with men, these delays could potentially have important consequences for public health $[4,5]$. The importance of identifying transmission clusters through phylogenetic analyses among this sub-population thus becomes particularly relevant. The results of such analyses could then be used to advocate for either point-of-care HIV testing at the time of entry or as part of the IME, moving towards a "test-and-treat" model of care for this population.

Previously diagnosed asylum seekers who arrived in Canada without a supply of antiretrovirals are another priority group for accelerated linkage to HIV care. While these individuals represented only $23 \%$ of those with previously known HIV, their immune systems appeared to be more compromised than newly diagnosed asylum seekers; their median CD4 count was 242 cells/ $\mu$ l vs. 307 cells/ $\mu$, respectively. Individuals with known HIV are expected to declare their status at the border, at which point, they are referred to AIDS service organizations (ASOs) for accelerated linkage to care. This information (i.e. disclosure of status and referrals to ASOs) was not extracted by our retrospective chart reviews; however, there was a median of 71 days between entry into Canada and cART re-initiation, with the major bottleneck similarly occurring from entry to linkage (64 days). This suggests that disclosure may have rarely occurred at the time of border crossing, likely due to the fear of being denied entry into Canada. This also implies that there may be a role for the improved provision of information at the time of entry into Canada, including allaying fears regarding the denial of people living with HIV, and the availability of free medical care to reduce interruptions of therapy.

We found that the overall frequency of drug resistance among newly diagnosed asylum seekers was $21 \%-1.5$ fold higher than provincial (13.1\%) and national (13.9\%) levels $[25,26]$. It is unclear whether the higher observed resistance rates represent true transmitted resistance, prior undisclosed treatment, or exposure to nevirapine in the context of prevention of mother-to-child transmission (MTCT) efforts. The frequency of both K103 N/S and M18 V/I resistance mutations was three-fold higher in our newly diagnosed population compared to provincial data. The K103 N/S mutation predominated, reflecting that efavirenz and nevirapine continue to be widely used in many developing countries. In fact, among the seven newly diagnosed individuals with a K103 N/S mutation, three were women with living children, suggesting that prior exposure to nevirapine for MTCT may have been possible. That said, the frequency of $\mathrm{K} 103 \mathrm{~N} / \mathrm{S}$ resistance mutations among treatment-experienced patients was identical to provincial data (17\%) [25]. Conversely, we observed a much lower frequency (4.3\%) of M184 V/I resistance mutations among treatment-experienced patients than the provincial frequency of $30 \%$, which may represent truly lower baseline rates or an underestimation due to M184 $\mathrm{V} / \mathrm{I}$ 's potential to be archived. Our findings imply that, although one in five newly diagnosed asylum seekers shows evidence of drug resistance, withholding cART while awaiting baseline genotypes is likely unnecessary. Providers should initiate a first-line integrase-based cART regimen as soon as possible, recognizing that M184 V/I resistance mutations are rare (or possibly underestimated) and that NNRTIs should be avoided (as per current guidelines) [27]. The baseline genotypic susceptibility scores of 
3 corroborate this; newly diagnosed patients were prescribed fully functional regimens even in the absence of available baseline genotypes. That said, baseline genotypic testing (including integrase) should still be done on everyone especially as first line regimens in developing countries are evolving to contain integrase inhibitors.

Our retrospective cohort study represents one of the first in Canada and globally to quantify the HIV care cascade among asylum seekers. Although our results are likely generalizable to asylum seekers in other Canadian provinces as identical care pathways exist (i.e. IME within 30 days of arrival, linkage via immigration medical doctors, etc.) throughout Canada, our analysis is limited to asylum seekers who are linked to care in a tertiary care centre with specialized HIV services. Our study has other limitations. First, there are important delays in the HIV care cascade that we were not able to accurately quantify. These include the time from cART prescription to cART initiation, as well as the true time to viral suppression given inconsistent VL measurements. Second, we were not powered to determine correlates associated with delays along the HIV care cascade although many sociodemographic (ethnicity, gender, sexual orientation, etc.) and psychosocial (financial or housing insecurity, HIV-related stigma, etc.) factors may have played a role as other studies have shown $[1,23]$. For example, while $40 \%$ of the study population reported a history of sexual- or gender-based violence, and certain ethnocultural groups reported worse financial strain than others, due to the retrospective nature of this study, validated tools were not used to assess these correlates. Future qualitative studies could add insight into how best to reduce delays in linkage to HIV care for asylum seekers.

\section{Conclusions}

Migrant populations represent an increasing proportion of people living with HIV in many developed countries such as Canada. Our study has demonstrated that even in a system with a clearly defined care pathway, there is a need to expedite screening and linkage to HIV care for asylum seekers. This may be in the form of either pointof-care HIV testing at the time of entry or as part of the IME, moving towards a "test-and-treat" model of care. With globalization and current trends in migration, prioritizing migrant populations in HIV care engagement will not only have important individual-level health outcomes, but will benefit society as a whole.

\footnotetext{
Abbreviations

CART: Combination antiretroviral therapy; CDC: Centre for Disease Control and Prevention; CVIS: Chronic Viral IIIness Service; GSS: Genotypic susceptibility score; HIV: Human immunodeficiency virus; HIVdb: HIV database; IFHP: Interim Federal Health Program; II: Integrase inhibitor; IME: Immigration medical exam; IQR: Interquartile range; IRCC: Immigration, Refugees and Citizenship Canada; MTCT: Mother-to-child transmission;
}

MUHC: McGill University Health Centre; NNRTI: Non-nucleoside reverse transcriptase inhibitor; NRTI: Nucleoside reverse transcriptase inhibitor; Ol: Opportunistic infection; PI: Protease inhibitor; PRAIDA: Programme Régional d'Accueil et d'Intégration des Demandeurs d'Asile; TAMs: Thymidine analogue mutations; VL: Viral load

\section{Acknowledgements}

We would like to acknowledge Claire Duchesneau in assisting with data collection.

\section{Authors' contributions}

As the corresponding author, NK has had full access to all the data in the study and takes responsibility for the integrity of the data and the accuracy of the data analysis. Study concept and design: NK; Statistical analysis: BL1; Drafting of the manuscript: NK; Acquisition, analysis or interpretation of data: NK, BL1, NS, JC, IH, BL2, AP, CF, MR, MK; Critical revision of the manuscript for important intellectual content: NK, BL1, NS, JC, IH, BL2, AP, CF, MR, MK. All authors have read and approved the final version of the manuscript.

Funding

Not applicable.

\section{Availability of data and materials}

The data generated and/or analysed during the current study are not publicly available due to privacy regulations, but de-identified data are available from the corresponding author on reasonable request.

Ethics approval and consent to participate

This study was approved by the Research Institute of the McGill University Health Centre Research Ethics Board (MUHC 2019-5037). Given the retrospective nature of the study, patient consent was not obtained.

\section{Consent for publication}

Not applicable. All our data are anonymised. We have removed any specific contextual identifiers and used systematic codes.

\section{Competing interests}

None of the authors feel in conflict of interest with regards to this study and there was no pharmaceutical industry support to conduct this study. Blake Linthwaite, Nancy Sheehan, Isabelle Hardy, Charles Frenette and Michel Roger have no conflicts of interest to declare. Nadine Kronfli has received consulting fees from ViiV Healthcare, Merck and Gilead; research funding from Gilead; and payment for lectures from Gilead. Joseph Cox has received consulting fees from ViiV Healthcare and Gilead; research funding from ViiV Healthcare, Merck and Gilead; and payment for lectures from Gilead. Bertrand Lebouché has received consulting fees from ViiV Healthcare, Merck and Gilead; research funding from Merck, Gilead and Abbvie; and payment for lectures from Merck and Gilead. Alexandra de Pokomandy has received consulting fees from ViiV Healthcare. Marina B. Klein has received consulting fees from ViiV Healthcare, BMS, Merck, Gilead and AbbVie; and research funding from Merck, Gilead and ViiV Healthcare.

\section{Author details \\ 'Department of Medicine, Division of Infectious Diseases and Chronic Viral IIlness Service, Glen site, McGill University Health Centre, 1001 Decarie Boulevard D02.4110, Montreal, Quebec H4A 3J1, Canada. ${ }^{2}$ Research Institute of the McGill University Health Centre, Montreal, Quebec, Canada. ${ }^{3}$ Faculté de Pharmacie, Université de Montréal, Montreal, Quebec, Canada. \\ ${ }^{4}$ Département de Microbiologie, Infectiologie et Immunologie, Université de Montréal, Montreal, Quebec, Canada. ${ }^{5}$ Department of Family Medicine, McGill University, Montreal, QC, Canada. ${ }^{6}$ Centre Hospitalier de l'Université de Montréal, Montreal, Quebec, Canada. ${ }^{7}$ CIHR Canadian HIV Trials Network, Vancouver, British Columbia, Canada.}

Received: 13 August 2019 Accepted: 9 December 2019

Published online: 16 December 2019

\section{References}

1. Fakoya I, Álvarez-Del Arco D, Monge S, Copas AJ, Gennotte AF, Volny-Anne A, et al. HIV testing history and access to treatment among migrants living 
with HIV in Europe. J Int AIDS Soc. 2018;21:e25123 Available from: https:// doi.org/10.1002/jia2.25123. [cited 2019 Aug 08].

2. Gunaratnam P, Heywood AE, McGregor S, Jamil MS, McManus H, Mao L, et al. HIV diagnoses in migrant populations in Australia-A changing epidemiology. PloS one. 2019;14(2):e0212268 Available from: https://doi.org/ 10.1371/journal.pone.0212268. [cited 2019 Aug 08]

3. del Amo J, Pérez-Cachafeiro S, Hernando V, González C, Jarrí I, Bolúmar F. Migrant health: epidemiology of HIV and AIDS in migrant communities and ethnic minorities in EU/EEA countries: European centre for disease prevention and control (ECDC); 2010. Available from: https://ecdc.europa.eu/ sites/portal/files/media/en/publications/Publications/0907_TER_Migrant_ health_HIV_Epidemiology_review.pdf. [cited 2019 Mar 08].

4. Mole RC, Parutis V, Gerry CJ, Burns FM. The impact of migration on the sexual health, behaviours and attitudes of Central and East European gay/ bisexual men in London. Ethn Health. 2014;19(1):86-99 Available from: https://doi.org/10.1080/13557858.2013.789829. [cited 2019 Aug 08].

5. Pachankis JE, Hatzenbuehler ML, Hickson F, Weatherburn P, Berg RC, Marcus $U$, et al. Hidden from health: structural stigma, sexual orientation concealment, and HIV across 38 countries in the European MSM Internet Survey. AIDS (Lond, Engl). 2015;29(10):1239 Available from: https://www. ncbi.nlm.nih.gov/pmc/articles/PMC4820755/. [cited 2019 Aug 08].

6. Fakoya I, Álvarez-del Arco D, Woode-Owusu M, Monge S, Rivero-Montesdeoca Y, Delpech V, et al. A systematic review of post-migration acquisition of HIV among migrants from countries with generalised HIV epidemics living in Europe: Implications for effectively managing HIV prevention programmes and policy. BMC Public Health. 2015;15(1):561 Available from: https://doi.org/10. 1186/s12889-015-1852-9. [cited 2019 Aug 08].

7. Li A. Immigrants, refugees and non-status people with HIV: Canadian AIDS Treatment Information Exchange (CATIE); 2009. Available from: https://www. catie.ca/en/practical-guides/managing-your-health/17. [cited 2019 Mar 08].

8. Government of Canada. Asylum claims by year - 2011 - 2016: Canada.ca; c2018. Available from: https://www.canada.ca/en/immigration-refugeescitizenship/services/refugees/asylum-claims/processed-claims.html. [updated 2019 Feb 15; cited 2019 Mar 08].

9. Government of Canada, Government of the United-States of America. Agreement between the Government of Canada and the Government of the United States of America for Cooperation in the Examination of Refugee Status Claims from Nationals of Third Countries: Canada.ca; 2002. Available from: https://www.canada.ca/en/immigration-refugees-citizenship/ corporate/mandate/policies-operational-instructions-agreements/ agreements/safe-third-country-agreement/final-text.html. [updated 2016 Jun 23; cited 2019 Mar 08].

10. Government of Canada. Who must submit to an immigration medical examination? : Canada.ca; c2018. Available from: https:/www.canada.ca/en/ immigration-refugees-citizenship/corporate/publications-manuals/ operational-bulletins-manuals/standard-requirements/medical-requirements/ exam/who-must-submit-immigration-medical-examination.html. [updated 2017 Nov 10 cited 2019 Mar 08]

11. Bourgeois AC, Edmunds M, Awan A, Jonah L, Varsaneux O, Siu W-K. HIV in Canada-Surveillance Report, 2016. Can Commun Dis Rep. 2017;43(12): 248-56 Available from: https://dx.doi.org/10.14745\%2Fccdr.v44i12a03. [cited 2019 Aug 08].

12. Government of Canada. Interim Federal Health Program: Summary of coverage: Canada.ca; c2018. Available from: https://www.canada.ca/en/ immigration-refugees-citizenship/services/refugees/help-within-canada/ health-care/interim-federal-health-program/coverage-summary.html. [updated 2018 Oct 12; cited 2019 Mar 08]

13. Haddad N, Li J, Totten S, McGuire M. HIV in Canada-Surveillance Report, 2017. Can Commun Dis Rep. 2018;44(12):324-32 Available from: https://doi. org/10.14745/ccdr.v44i12a03. [cited 2019 Aug 08].

14. Joint United Nations Programme on HIV/AIDS. 90-90-90: an ambitious treatment target to help end the AIDS epidemic: UNAIDS 2014. Available from: http://www.unaids.org/sites/default/files/media_asset/90-90-90_en.pdf. [cited 2019 Mar 08]

15. Centers for Disease Control and Prevention (CDC). Understanding the HIV Care Continuum: CDC 2018. Available from: https://www.cdc.gov/hiv/pdf/ library/factsheets/cdc-hiv-care-continuum.pdf. [cited 2019 Mar 08].

16. O'Laughlin K, Kasozi J, Rabideau D, Parker R, Mulogo E, Faustin Z, et al. The cascade of HIV care among refugees and nationals in Nakivale Refugee Settlement in Uganda. HIV Med. 2017;18(7):513-8 Available from: https://doi. org/10.1111/hiv.12476. [cited 2019 Aug 08].
17. Stanford HIV Drug resistance database. Available from: https://hivdb. stanford.edu/. [cited 2019 Mar 08]

18. Frentz D, Boucher CA, Assel M, De Luca A, Fabbiani M, Incardona F, et al. Comparison of HIV-1 genotypic resistance test interpretation systems in predicting virological outcomes over time. PloS one. 2010;5(7):e1 1505 Available from: https://doi.org/10.1371/journal.pone.0011505. [cited 2019 Aug 08].

19. Ryom L, Boesecke C, Bracchi M, Ambrosioni J, Pozniak A, Arribas J, et al. Highlights of the 2017 European AIDS Clinical Society (EACS) Guidelines for the treatment of adult HIV-positive persons version 9.0. HIV Med. 2018;19(5):309-15 Available from: https://doi.org/10.1111/hiv. 12600. [cited 2019 Aug 08].

20. Ross J, Cunningham CO, Hanna DB. HIV outcomes among migrants from low-income and middle-income countries living in high-income countries: A review of recent evidence. Curr Opin Infect Dis. 2018;31(1):25-32 Available from: https://europepmc.org/articles/pmc5750122. [cited 2019 Aug 08].

21. Op de Coul EL, Van Sighem A, Brinkman K, van Benthem BH, van der Ende $M E$, Geerlings $S$, et al. Factors associated with presenting late or with advanced HIV disease in the Netherlands, 1996-2014: results from a national observational cohort. BMJ Open. 2016;6(1):e009688 Available from: http://dx. doi.org/10.1136/bmjopen-2015-009688. [cited 2019 Aug 08].

22. Hernando V, Alvárez-del Arco D, Alejos B, Monge S, Amato-Gauci AJ, Noori $\mathrm{T}$, et al. HIV infection in migrant populations in the European Union and European Economic Area in 2007-2012: An epidemic on the move. J Acquir Immune Defic Syndr. 2015;70(2):204-11 Available from: https://journals.Iww. com/jaids/fulltext/2015/10010/HIV_Infection_in_Migrant_Populations_in the.14.aspx. [cited 2019 Aug 08].

23. Government of Canada. Medical exam for permanent residents: Canada.ca; c2018. Available from: https:/www.canada.ca/en/immigration-refugeescitizenship/services/application/medical-police/medical-exams/ requirements-permanent-residents.html. [updated 2019 Jan 25; cited 2019 Mar 08].

24. Fakoya I, Álvarez-del Arco D, Copas AJ, Teixeira B, Block K, Gennotte A-F, et al. Factors associated with access to HIV testing and primary care among migrants living in Europe: cross-sectional survey. JMIR Public Health Surveill. 2017;3(4) Available from: https://doi.org/10.2196/publichealth.7741. [cited 2019 Aug 08].

25. Charest H, Doualla-Bell F, Cantin R, Murphy DG, Lemieux L, Brenner B, et al. A significant reduction in the frequency of HIV-1 drug resistance in Quebec from 2001 to 2011 is associated with a decrease in the monitored viral load. PloS one. 2014;9(10):e109420 Available from: https://doi.org/10.1371/journal. pone.0109420. [cited 2019 Aug 08].

26. Public Health Agency of Canada (PHAC). Update on HIV-1 Strain and Transmitted Drug Resistance in Canada: 2012-2013: Centre for Communicable Diseases and Infection Control - Public Health Agency of Canada i2 2017. Available from: https://www.canada.ca/en/public-health/ services/publications/diseases-conditions/hiv-canadian-strain-drugresistance-surveillance-2012-2013.html. [cited 8 March 2019].

27. Panel on Antiretroviral Guidelines for Adults and Adolescents. Guidelines for the Use of Antiretroviral Agents in Adults and Adolescents Living with HIV: US Department of Health and Human Services (DHHS); 2018 . Available from: http://aidsinfo.nih.gov/contentfiles/lvguidelines/ AdultandAdolescentGL.pdf. [updated 25 Oct 2018; cited 8 Mar 2019].

\section{Publisher's Note}

Springer Nature remains neutral with regard to jurisdictional claims in published maps and institutional affiliations.

\section{Ready to submit your research? Choose BMC and benefit from:}

- fast, convenient online submission

- thorough peer review by experienced researchers in your field

- rapid publication on acceptance

- support for research data, including large and complex data types

- gold Open Access which fosters wider collaboration and increased citations

- maximum visibility for your research: over $100 \mathrm{M}$ website views per year

At $\mathrm{BMC}$, research is always in progress.

Learn more biomedcentral.com/submissions 